\title{
Seasonal Sea Surface Temperature Asymmetry in the Northwestern Pacific Marginal Seas
}

\author{
Hyeonyeong Kwak ${ }^{1,2}$, Yang-Ki Cho ${ }^{1, *}$, Gwang-Ho Seo ${ }^{1,4}$, Yong-Jin Tak ${ }^{1}$, Hyo-Seok Park ${ }^{1}$, \\ Sung Hyup You ${ }^{3}$, and Jang-Won Seo ${ }^{3}$ \\ ${ }^{1}$ School of Earth and Environmental Sciences/Research Institute of Oceanography, Seoul National University, Seoul, Korea \\ ${ }^{2}$ Department of Oceanographic Survey, GeoSystem Research Corporation, Gunpo, Korea \\ ${ }^{3}$ Marine Meteorology Division, Observation and Infrastructure Bureau, Korea Meteorological Administration, Seoul, Korea \\ ${ }^{4}$ Oceanographic Forecast Division, Korea Hydrographic and Oceanographic Administration, Busan, Korea
}

Received 24 March 2014, revised 18 November 2014, accepted 21 November 2014

\begin{abstract}
Sea surface temperature (SST) is an important component of climate and weather systems at various time scales. Asymmetric seasonal SST variations in the Northwestern Pacific Marginal Seas (NWPMS) are investigated in this study using observation data and numerical model results. The asymmetry in SST seasonal variation is estimated quantitatively and compared with heat advection and surface net heat flux using SST data and atmospheric variables from the European Centre for Medium-Range Weather Forecast (ECMWF). The SST increases faster than it decreases, whereas air temperature increases slowly. Heat advection and surface heat flux were estimated using numerically modeled SST and ocean currents, which contribute to the asymmetry of seasonal SST variations. Heat advection shows good correlation with the SST seasonal variation asymmetry. Model results without currents along the boundary show more symmetrical SST variations. This suggests that heat advection is a prominent cause of asymmetry in the seasonal variation.
\end{abstract}

Key words: Sea surface temperature, Seasonal variation, Asymmetry, Surface heat flux, Heat advection

Citation: Kwak, H., Y. K. Cho, G. H. Seo, Y. J. Tak, H. S. Park, S. H. You, and J. W. Seo, 2015: Seasonal Sea Surface Temperature asymmetry in the Northwestern Pacific Marginal Seas. Terr. Atmos. Ocean. Sci., 26, 331-340, doi: 10.3319/TAO.2014.11.21.01(Oc)

\section{INTRODUCTION}

Sea surface temperature (SST) plays a key role in changing climate and weather systems at various time scales, specifically via air-sea momentum and heat exchange processes. Therefore, research on SST variation is fundamental and crucial for understanding the oceans, atmosphere, fisheries, and ecology. Furthermore, the seasonal variation in water temperature has a large impact on primary production and marine habitats (Wang et al. 2003; Belkin 2009).

While the seasonal variation in SST is qualitatively measured in many regional seas, relatively little attention has been given to understanding the asymmetric SST seasonal variation. The asymmetry is of interest because it reflects the complexities of ocean dynamics, which includes nonlinear processes (Bartos and Jánosi 2005, 2006).

The asymmetric seasonal variation in air temperature,

\footnotetext{
* Corresponding author

E-mail:choyk@snu.ac.kr
}

characterized by rapid cooling and gradual warming in midlatitudes has been studied (Ashkenazy et al. 2008). However, relatively little research has been done to understand the asymmetric SST seasonal variation, which can influence air temperature at various time scales. SSTs influence surface winds (Wallace et al. 1989) that in turn affect the SSTs via air-sea interactions. Understanding the air-sea interaction and surface heat fluxes is an important prerequisite to explain SST variations (Cayan 1992; Hirose et al. 1999; Subrahamanyam et al. 2008).

The SST is influenced by air-sea interactions and also ocean heat advection from ocean currents. The Kuroshio and Tsushima Currents (KC and TC) are the most important pathways for heat transport, causing SST variations in the Northwestern Pacific Marginal Seas (NWPMS) (Fig. 1). The seasonal variation in SST and its asymmetry might be strongly influenced by air-sea interaction and heat advection in the NWPMS (Kang 1984; Dong et al. 2007; Cho et al. 2009, 2013; Seo et al. 2014). 
The main objective of this study is to quantitatively assess the SST seasonal variation asymmetry in the NWPMS and ascertain the spatial distribution of the asymmetry. The role of horizontal ocean heat advection on the SST asymmetry will also be discussed.

\section{DATA AND METHODOLOGY}

\subsection{Data}

Both satellite observed and model simulated SST data are used. The satellite data is from the Operational Sea Surface Temperature and Sea Ice Analysis (OSTIA), provided by the UK Met Office (Donlon et al. 2012). This system combines in situ data with infrared and microwave satellite data. The data is available daily and has global coverage with a spatial resolution of $1 / 20^{\circ}$. Recent OSTIA SST may be higher than climate SST provided by National Oceanographic Data Center (http://www.nodc.noaa.gov/OC5/regional climate/KPRclimatology/) due to rapid warming in the study area (Belkin 2009).

The model simulated SST data is from the Regional Ocean Modeling System (ROMS), simulated from 1993 2011. The model domain is $117.5-154.5^{\circ} \mathrm{E}$ and $18.5-48.5^{\circ} \mathrm{N}$, including the East China Sea, Yellow Sea, East/Japan Sea, and Northwestern Pacific. The ocean model has a horizontal resolution of $0.1^{\circ}$ and 20 vertical levels. Simple Ocean Data Assimilation (SODA) from 1993 - 2010, and Hybrid Coordinate Ocean Model (HYCOM) data from 2011 were used as open boundary data. Surface forcing was from the European Centre for Medium-Range Weather Forecast (ECMWF) interim daily data. Ten major tidal forcings were applied (Egbert and Erofeeva 2002) and twelve rivers were included. The vertical mixing scheme used was the K-Profile parameterization (Large et al. 1994). Further details of the model follow Seo et al. (2014). Model-simulated SSTs from 2006 - 2010 are used to calculate the seasonal variation of SSTs.

Atmospheric variables such as air temperature and wind stress from the ECMWF interim daily data with horizontal resolution of $0.75^{\circ}$ are used to calculate surface heat fluxes.

\subsection{Heat Advection and Surface Heat Flux Calculation}

Heat advection is given by

$Q=\iint \rho c_{p} T(z) U(z) d z d x$

where $\rho$ is the sea water density, $c_{p}$ is the heat capacity of sea water, and $T(z)$ and $U(z)$ are the temperature and current velocity, respectively, at depth $z$.

The surface net heat flux $Q_{n e t}$ is given by

$Q_{n e t}=Q_{s}-\left(Q_{b}+Q_{h}+Q_{e}\right)$ where $Q_{s}$ is solar radiation, $Q_{b}$ is long-wave radiation, $Q_{h}$ is sensible heat flux, and $Q_{e}$ is latent heat flux. If $Q_{\text {net }}$ is positive, the ocean gains heat from the atmosphere. Four components, $Q_{s}, Q_{b}, Q_{h}$, and $Q_{e}$, are estimated by empirical formulas as follows (Efimova 1961; Seckel and Beaudry 1973; Kim and Kimura 1995).

$Q_{s}=\left(0.865-0.5 C^{2}\right)(1-\alpha) Q_{0}$

$Q_{0}=A_{0}+A_{1} \cos \phi+B_{1} \sin \phi+A_{2} \cos 2 \phi+B_{2} \sin 2 \phi$

where $\phi=(t-21)(360 / 365), C$ is the amount of cloud, $\alpha$ is albedo, $t$ is Julian day, and the coefficients of $Q_{0}$ follow Table 1.

$Q_{b}=\epsilon \sigma T_{a}^{4}\left(0.254-0.00495 e_{a}\right)(1-\delta C)+4 \epsilon \sigma T_{a}^{3}\left(T_{s}-T_{a}\right)$

$Q_{h}=\rho_{a} c_{p a} c_{h}\left(T_{s}-T_{a}\right) W$

$Q_{e}=\rho_{a} L c_{e}\left(q_{s}-q_{a}\right) W$

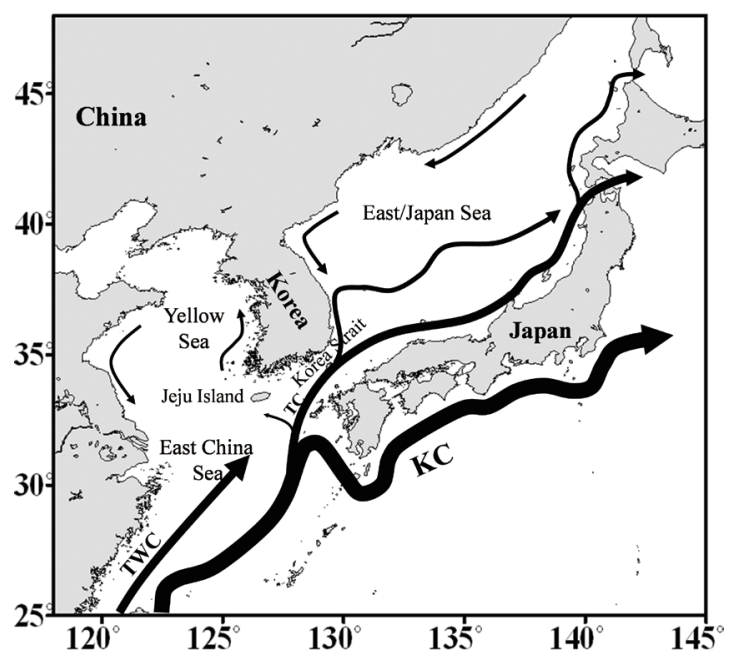

Fig. 1. Major ocean currents in the study area. KC, TWC, and TC represent the Kuroshio Current, Taiwan Warm Current, and Tsushima Current, respectively.

Table 1 . The coefficients used to calculate $Q_{0}$ (Seckel and Beaudry 1973).

\begin{tabular}{c|c|c}
\hline & Latitude $\mathbf{2 0}^{\circ} \mathbf{S}-\mathbf{4 0}^{\circ} \mathbf{N}$ & Latitude $40^{\circ} \mathbf{N}-\mathbf{6 0}^{\circ} \mathbf{N}$ \\
\hline$A_{0}$ & $-15.82+326.87 \cos L$ & $342.61-1.97 L-0.018 L^{2}$ \\
$A_{1}$ & $9.63+192.44 \cos (L+90)$ & $52.08-5.86 L+0.043 L^{2}$ \\
$B_{1}$ & $-3.27+108.7 \sin L$ & $-4.80+2.46 L-0.017 L^{2}$ \\
$A_{2}$ & $-0.64+7.80 \sin 2(L-45)$ & $1.08-0.47 L+0.011 L^{2}$ \\
$B_{2}$ & $-0.50+14.42 \cos 2(L-5)$ & $-38.79+2.43 L-0.034 L^{2}$ \\
\hline
\end{tabular}

Note: L: latitude. 
where the emissivity of the sea surface, $\epsilon$ is 0.97 , the StefanBoltzmann constant $\sigma$ is $5.67 \times 10^{-8} \mathrm{~W} \mathrm{~m}^{-2} \mathrm{~K}^{-4}$, cloud coefficient $\delta=0.60$, air density $\rho_{a}=1.125 \mathrm{~kg} \mathrm{~m}^{-3}, c_{p a}=1.048$ $\times 10^{3} \mathrm{~J} \mathrm{~kg}^{-1} \mathrm{~K}^{-1}$, bulk transfer coefficients $c_{h}=1.1 \times 10^{-3}$, $c_{e}=1.2 \times 10^{-3} . T_{s}$ and $T_{a}$ are SST and air temperature, respectively. $e_{a}$ is vapor pressure, $W$ is wind speed, $L$ is latent heat of evaporation, $q_{s}$ is saturated specific humidity at $T_{s}$, and $q_{e}$ is specific humidity.

\section{RESULTS}

\subsection{Seasonal Air Temperature and SST Variation Asymmetry}

The Day Ratio (DR) is defined to quantify the asymmetry in the seasonal temperature variation. This study defines DR as the ratio of the number of days of increasing temperature to the total period from 2006 - 2010.

$\mathrm{DR}=$ Number of days of temperature increasing trend / total period (2006 - 2010)

Therefore, the seasonal variation in temperature is symmetric if DR is 0.5 . A DR value larger (smaller) than 0.5 implies that the temperature warms (cools) gradually and cools (warms) rapidly.

Figure 2 shows the DR spatial distribution for air temperature and SST. The DR for air temperature is over 0.5 for the whole area, whereas the DR for SST is less than 0.5, except in some coastal regions. This means that the seasonal air temperature increases slowly, whereas SSTs increase rapidly. It is notable that the DR of SST is less than 0.3 , and the period of decreasing temperature is more than twice the period of increasing temperature, in the Kuroshio path.

\subsection{Harmonic Analysis of Air Temperature and SST}

Only the annual variation exists if the seasonal temperature variation is symmetric. However, seasonal variations in both air temperature and SST are asymmetric, as shown in Fig. 2. Spectral SST analysis shows that annual and semiannual variations are dominant in the study area.

Harmonic analysis is used to resolve the annual and semi-annual temperature variations.

$T_{i}=\bar{T}+A_{1} \cos \left(\omega_{1} t_{i}-\phi_{1}\right)+A_{2} \cos \left(\omega_{2} t_{i}-\phi_{2}\right)$

where $\bar{T}$ is mean temperature, $A_{1}$ and $A_{2}$ denote the annual and the semi-annual amplitudes, respectively, $\omega_{1}$ and $\omega_{2}$ are angular velocities, $\phi_{1}$ and $\phi_{2}$ denote the annual and the semiannual phases, respectively, at each grid, at time step $i$.

The amplitudes in annual variation in air temperature and SSTs range from $6-15^{\circ} \mathrm{C}$ and from $4-12^{\circ} \mathrm{C}$, respectively (Figs. 3a and b). The annual amplitudes are larger in the north than in the south. The semi-annual amplitude of air temperature is $0.5-2.5^{\circ} \mathrm{C}$, which is smaller than the annual amplitude (Fig. 3c). Consistent with the annual amplitude the semi-annual amplitude is larger in the north. In the northern East/Japan Sea the amplitude of semi-annual temperature variation is larger than $2.0^{\circ} \mathrm{C}$ (Fig. 3d). While the annual SST amplitude is smaller than that of air temperature the semi-annual SST amplitude is comparable to that of air temperature. The semi-annual SST amplitude is small along the coastal areas of China, Korea, and Japan and peaks on the coast of Russia, especially in the northern East/Japan Sea.

The annual air temperature phase is $210-230^{\circ}$ and less than $210^{\circ}$ in the coastal region (Fig. 4a). In contrast the semi-annual air temperature phase is $120-150^{\circ}$ and is large in the coastal areas (Fig. 4c). The annual SST phase is faster than that of air temperature by $10-20^{\circ}$ and is relatively fast along the coast (Fig. 4b). The semi-annual SST phase is less than $120^{\circ}$, and is generally faster than that of air temperature (Fig. 4d).

The temperature variation is symmetric when the semiannual variation amplitude is negligible compared to that of the annual variation. If the amplitude ratio (AR), defined as the semi-annual AR to the annual amplitude is large, the seasonal temperature variation might be asymmetric. DR and AR spatial distributions show similar features except in the northern East/Japan Sea, where the annual and semi-annual phase differences are significant. The air temperature $\mathrm{AR}$ is less than 0.20 in the whole area, less than 0.10 along (a)

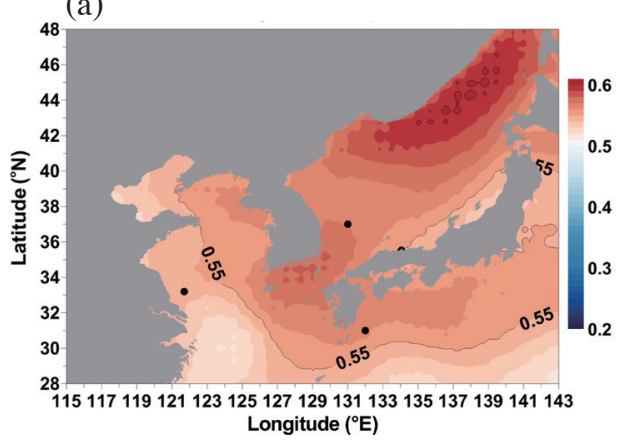

(b)

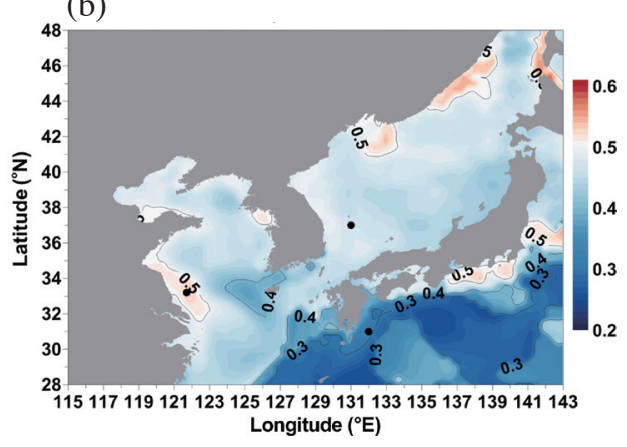

Fig. 2. DR of (a) air temperature and (b) SST. 
(a)

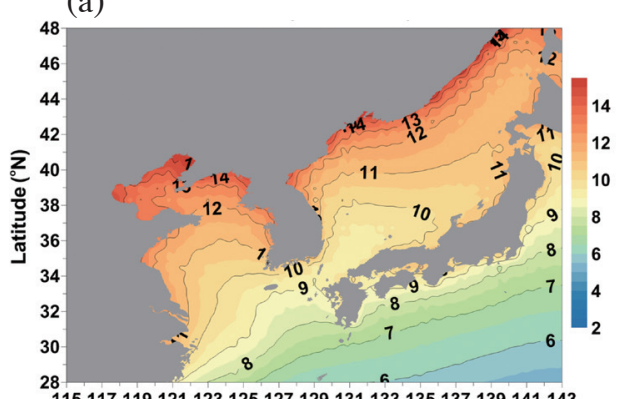

(c)

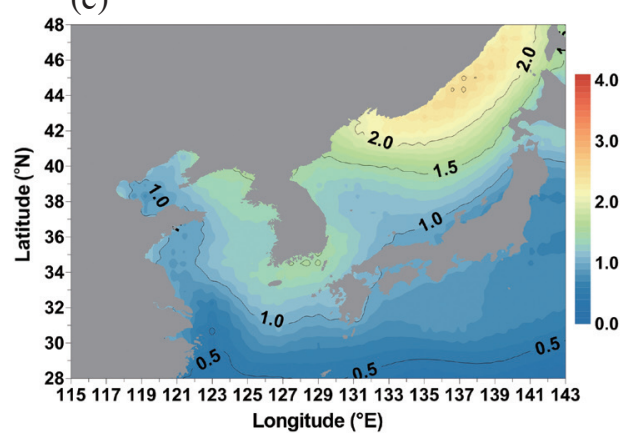

(b)

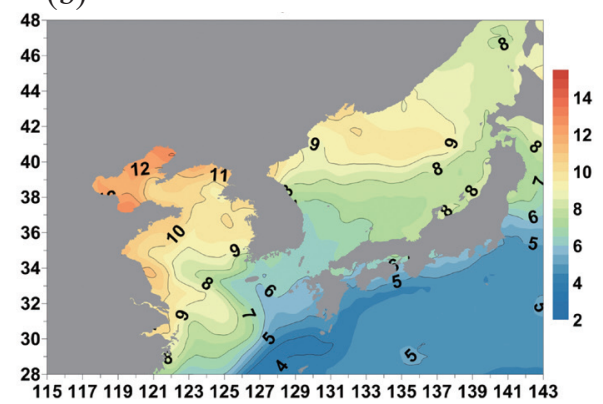

(d)

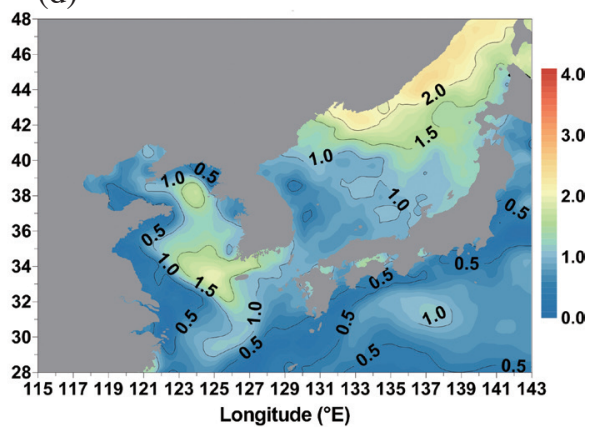

Fig. 3. Annual amplitude $\left({ }^{\circ} \mathrm{C}\right.$ ) of (a) air temperature and (b) SST, and semi-annual amplitude $\left({ }^{\circ} \mathrm{C}\right.$ ) of (c) air temperature and (d) SST.

(a)

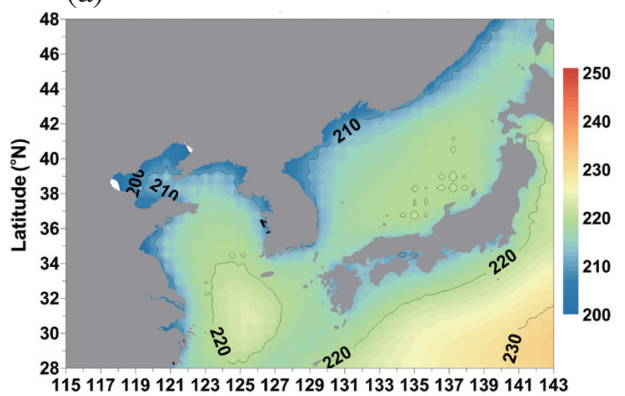

(c)

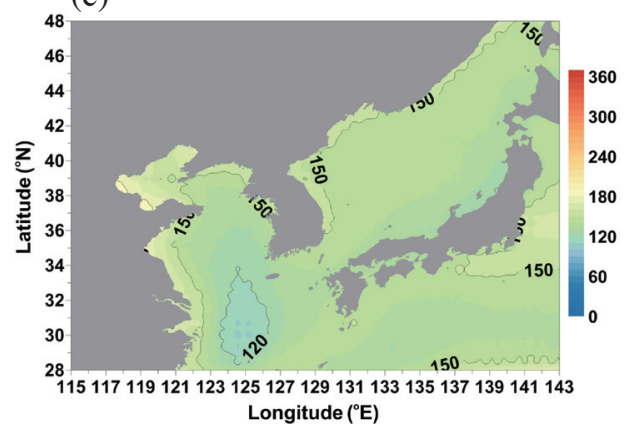

(b)

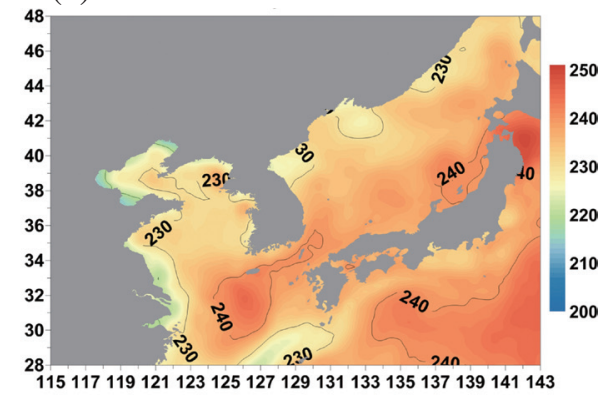

(d)

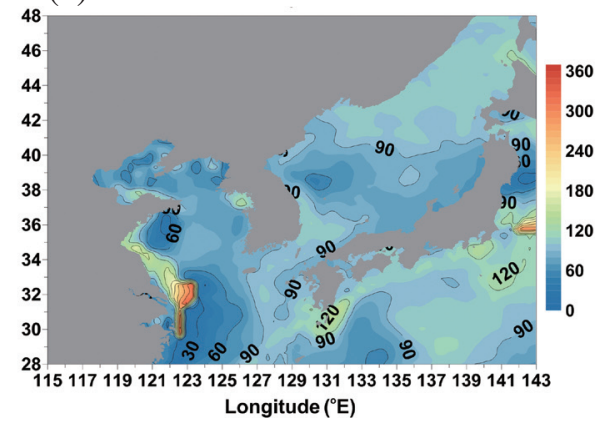

Fig. 4. Annual phase $\left(^{\circ}\right)$ of (a) air temperature and (b) SST, and semi-annual phase $\left(^{\circ}\right.$ ) of (c) air temperature and (d) SST.

the coastal region of the Yellow Sea and large in the northern East/Japan Sea where the semi-annual amplitude is significantly large. Although the air temperature AR is small in the entire area, the SST AR shows a large value over 0.20 west of Jeju Island, the Pacific Ocean and the northern East/ Japan Sea (Fig. 5). This means that the semi-annual varia- tion in SST is affected by air-sea interactions and also by other factors such as ocean heat advection.

\subsection{Surface Heat Flux and Heat Advection}

In this section model-simulated SSTs and ocean current 
velocity are used to elucidate the relationship between heat advection and the asymmetry in the seasonal SST variation. Here, heat advection means only heat advection incoming to each grid. Before estimating the heat advection, the modelsimulated SSTs and DR are compared with those from satellite observed SSTs to validate the model results (Fig. 6). Model SSTs and satellite observed SSTs are highly correlated with a squared correlation coefficient (R-squared) of 0.99 .

The DR and AR spatial features are similar to those from the satellite observed SSTs (Fig. 7). The DR and AR correlation coefficients between the model and the observed SSTs are 0.71 and 0.87 , respectively. However, the area of gradual SST warming is slightly wider than observed, especially in coastal areas and the northern East/Japan Sea. On the other hand, SSTs cool more slowly in many areas in the model. The AR of the model-simulated SST is lower than that of the satellite-observed data, except in the Western Pacific. (a)

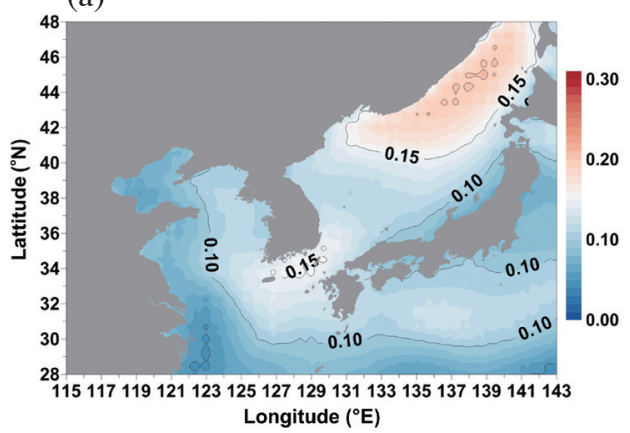

(b)

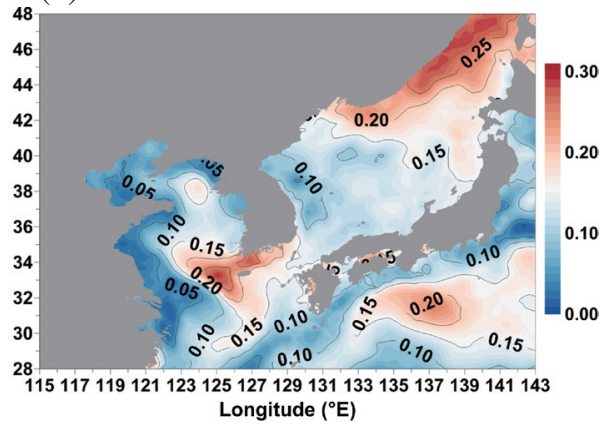

Fig. 5. AR of semi-annual to annual variations in (a) air temperature and (b) SST.

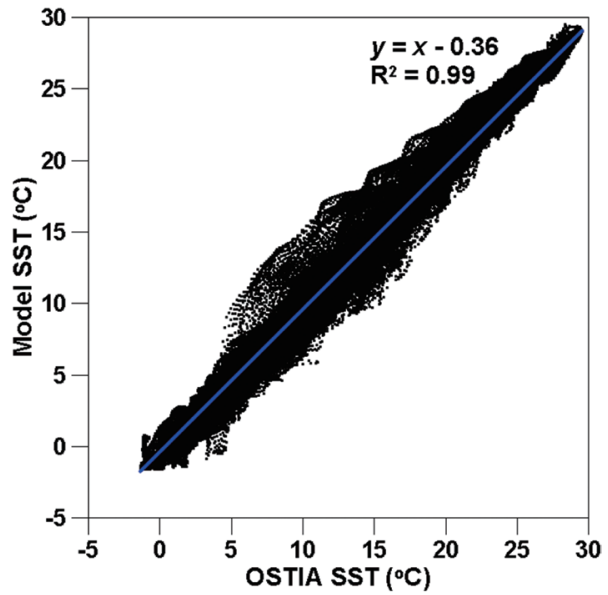

Fig. 6. Correlation between satellite-observed SSTs and model results.

(a)

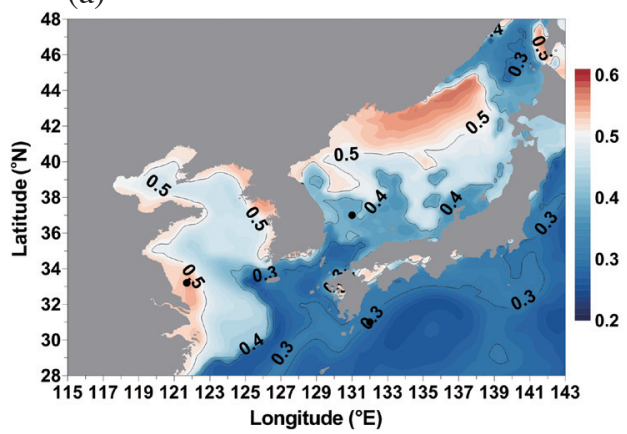

(b)

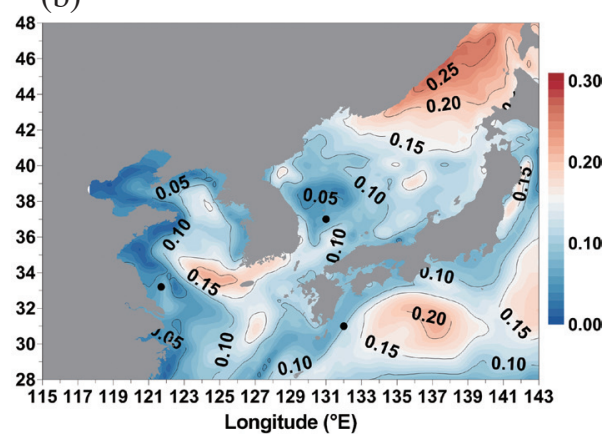

Fig. 7. (a) DR and (b) AR of model SST results. 
Surface net heat fluxes are estimated from the modelsimulated SSTs and atmospheric variables from the ECMWF. Five-year-averaged surface net heat fluxes are mostly positive in the coastal regions (Fig. 8b). The air-sea interaction is determined to be the most important factor for taking heat out of the ocean surface. The KC and TC flow regions show large negative surface fluxes. More than $10 \mathrm{GW}$ of heat is emitted into the air in those areas.

\section{DISCUSSION}

\subsection{The Role of Ocean Heat Advection and Surface Heat Fluxes on Seasonal SST Variations}

Correlations are calculated between the DR and the mean surface net heat flux and also between the DR and the heat advection in the surface 100-m layer from 2006 - 2010 (Fig. 9). The DR and the heat advection are negatively correlated, whereas the DR and the surface net heat flux are positively correlated. This is because the ocean loses more (less) heat by air-sea interaction over the regions where ocean heat advection is large (small).

We defined three groups spatially based on the DR; (1) $\mathrm{DR} \leq 0.33$, (2) $0.33<\mathrm{DR}<0.5$, and (3) $\mathrm{DR} \geq 0.5$. Where $\mathrm{DR} \leq 0.33$, SST decreases very slowly; these areas include the Western Pacific, Korean Strait, eastern East China Sea and northern East/Japan Sea, where warm currents flow. In coastal areas and the northern East/Japan Sea, DR $\geq 0.5$, and where heat advection is less than $1.0 \mathrm{TW}$, except on the coast of the northern East/Japan Sea. In those areas surface net heat fluxes are mostly positive (Figs. 10 and 11).

Three different regions, the Chinese coast in the Yellow Sea, the East/Japan Sea and the Kuroshio path (black dots labeled 1, 2, and 3 in Fig. 11), are chosen to examine the seasonal variation in SSTs, surface net heat fluxes and ocean heat advection in the 100-m surface layer (Fig. 12). At point 1, where ocean heat advection is dominant, the SST decreases very slowly and the mean ocean heat advection is remarkably as large as 269.89 TW (Table 2). In coastal areas, at point 3 , the increasing days for SST are longer than for cooling days. The mean ocean heat advection is small, the mean surface net heat fluxes are mostly positive and the DR is close to the DR of the air temperature. At point 2, in a transit area, both the ocean heat advection and surface net heat fluxes are approximately intermediate, between the values at points 1 and 3 .

Ocean heat advection accelerates SST warming in the spring, and slows down SST cooling in the fall. This effect is most notable in the Kuroshio path. Therefore, seasonal SST cools gradually, though the seasonal increase of air temperature is slower than the decrease.

\subsection{Asymmetry of SST Without Ocean Currents}

A model test without ocean currents was performed to evaluate the effect of heat advection on the asymmetric seasonal variation of SST. Currents along the open boundary and surface height anomaly were set to zero for the whole period. Surface elevation by tide was imposed.

Without heat advection by currents, the DR changes remarkably, showing more symmetric seasonal variation than when currents are present in the Northwestern Pacific, Korea Strait, and the East/Japan Sea (Fig. 13). In contrast, in the coastal region of the Yellow Sea, the seasonal SST variation becomes more asymmetric and warming is slower.

Seasonal SST at the three selected points, the Kuroshio path, the East/Japan Sea, and the coastal region of the Yellow Sea, are remarkably different from the SST variation when currents are present (Fig. 14). The mean temperature of the study area decreases due to the lack of heat supplied by the current from the southern boundary. The temperature increases more slowly and the period of increase becomes longer. The DRs are also close to 0.5 , which means the seasonal variation in SST is more symmetric (Table 3).

When there is no heat advection by ocean currents, the seasonal variation in SST becomes more symmetric. This model sensitivity test supports that heat advection is a major cause of asymmetric seasonal SST variation.

\section{CONCLUSION}

The seasonal variation in the SST is remarkably different from that of air temperature in the NWPMS. SST decreases slowly and increases rapidly, except in some coastal regions, whereas the air temperature in most regions increases slowly and decreases rapidly. Model results support the role of heat advection in the asymmetric SST variation.

The study area is divided into three parts according to the DR; an advection dominant area, a coastal area and a transit area. Where the seasonal SST warming is more gradual than cooling, heat advection is large (over $29 \mathrm{TW}$ ) and the ocean surface loses heat from air-sea interaction. On the other hand, where the seasonal SST increase is slower than the decrease, both heat advection and surface net heat flux are small.

The model result without ocean currents also supports the importance of heat advection to the SST variation asymmetry. When the currents along the open boundary were absent, the seasonal variation in SST was more symmetric, except in the coastal region of the Yellow Sea. This implies that heat advection is the main cause of the asymmetric seasonal SST variation. It is thought that in the spring and summer heat advection accelerates the temperature warming speed with the increasing trend of air temperature. In contrast, in the fall, heat advection decelerates the cooling speed against the decreasing air temperature. As a result, gradual cooling occurs in the ocean, although the rate of increase in air temperature is slower than the rate of decrease.

Since the heat advection was calculated only in the 
(a)

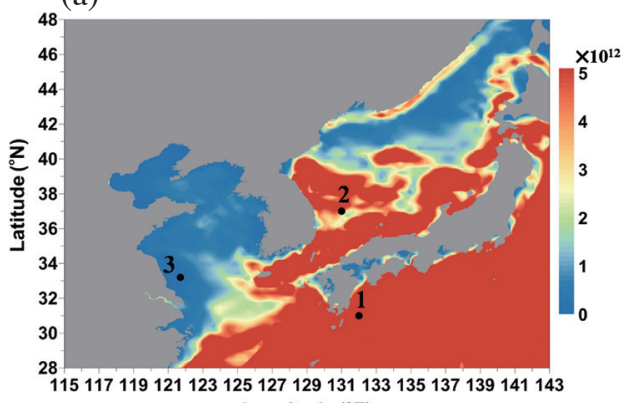

Longitude ( $\left.{ }^{\circ} \mathrm{E}\right)$ (b)

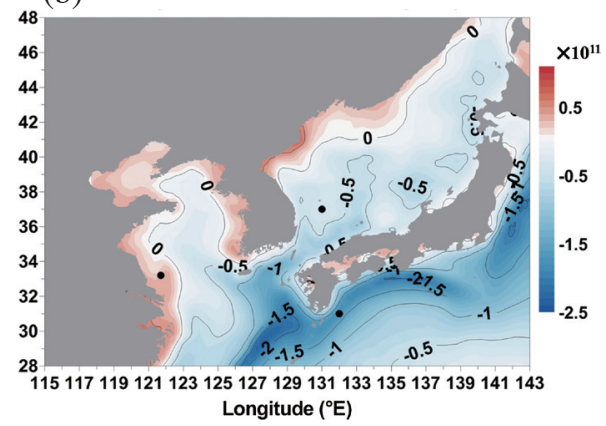

Fig. 8. (a) Mean heat advection (W) in the surface 100-m layer and (b) mean surface net heat flux (W) from 2006 - 2010. Numbers in left panel represent selected point for Figs. 12 and 13.

(a)

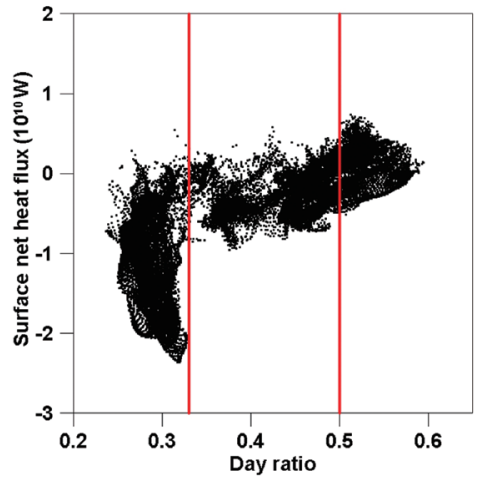

(b)

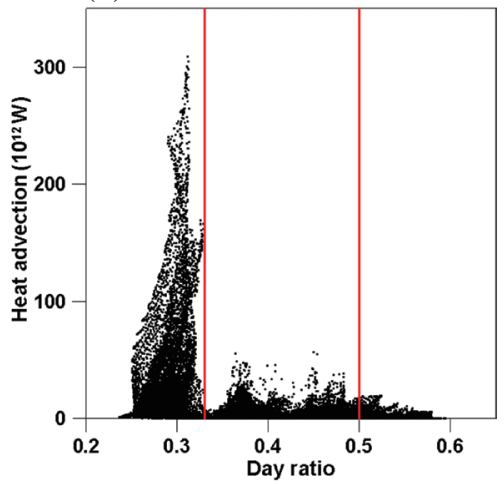

Fig. 9. Correlations (a) between DR and surface net heat flux and (b) between DR and incoming advection in the surface 100-m layer.

(a)

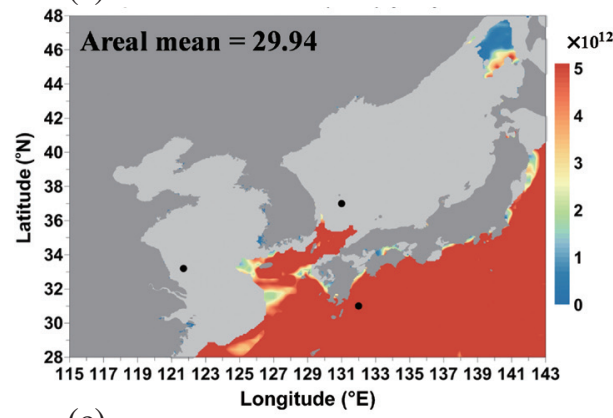

(c)

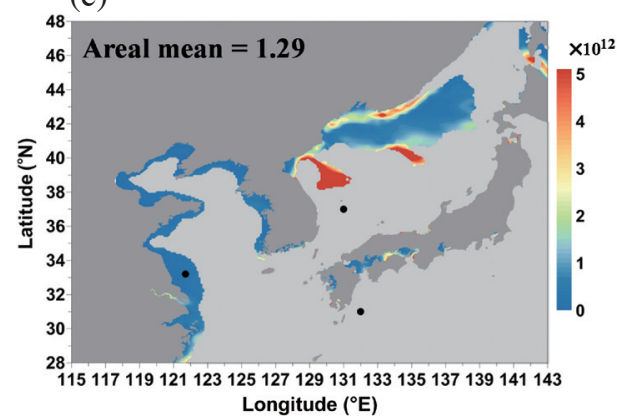

(b)

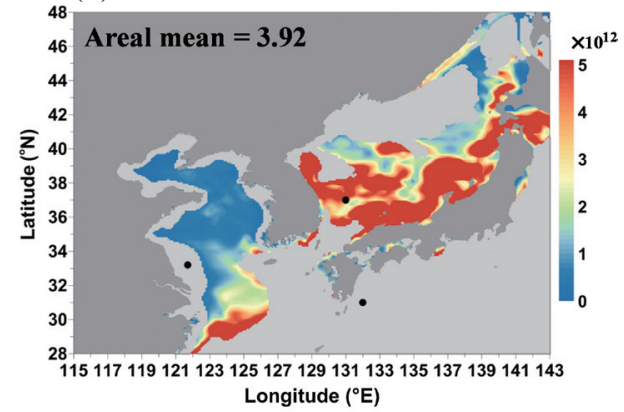

Fig. 10. Spatial distributions of mean incoming heat advection (W) from $2006-2010$ in each area (a) DR $\leq 0.33$, (b) $0.33<\mathrm{DR}<0.5$, and (c) $\mathrm{DR} \geq 0.5$. 
(a)

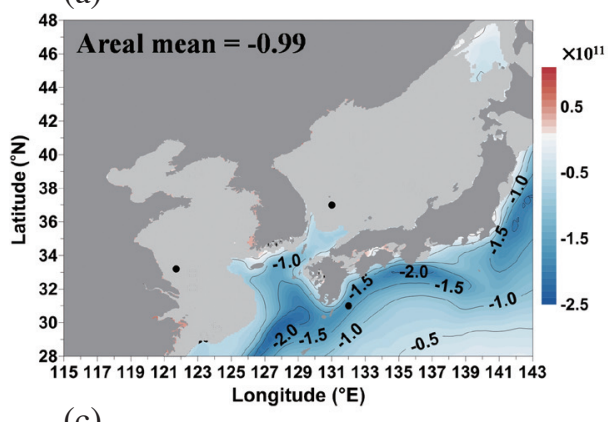

(c)

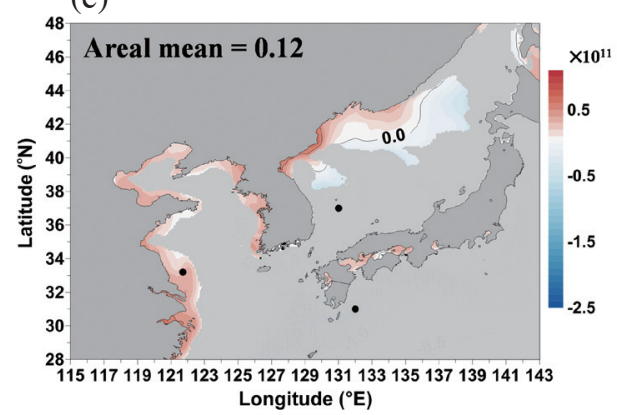

(b)

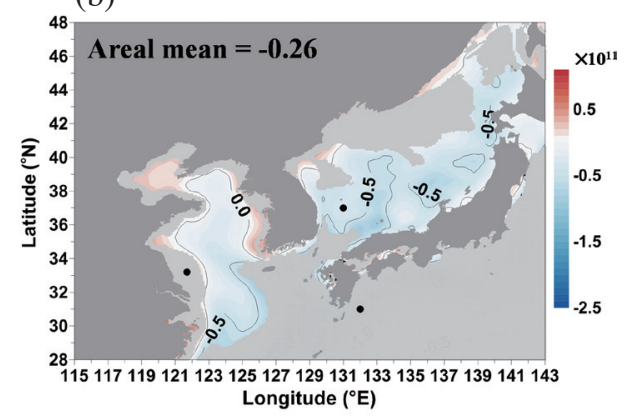

Longitude $\left({ }^{\circ} \mathrm{E}\right)$

Fig. 11. Spatial distributions of mean surface net heat flux (W) from 2006 - 2010 in each area (a) DR $\leq 0.33$, (b) $0.33<\mathrm{DR}<0.5$, and (c) DR $\geq 0.5$.
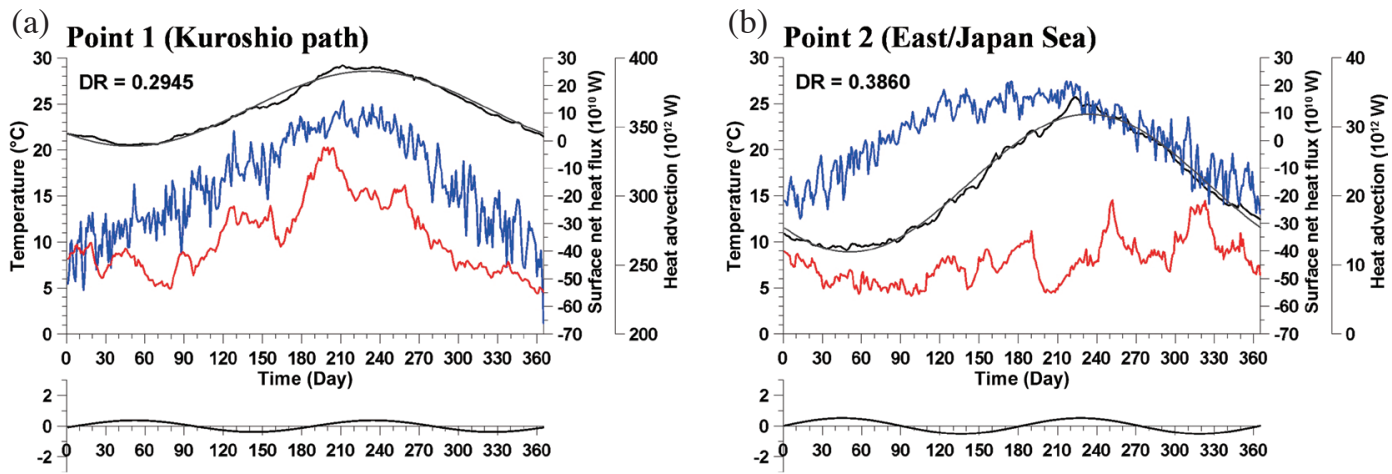

(c)

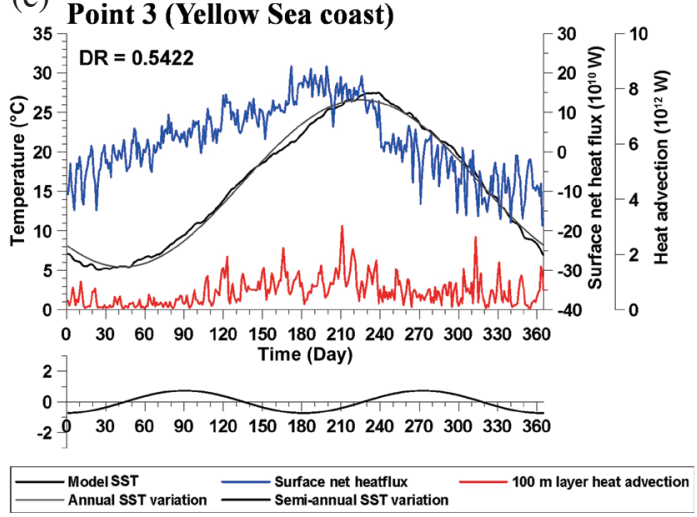

Fig. 12. Five-year-mean SST, 100-m layer heat advection, and surface net heat flux at points 1 - 3 (see Fig. 8 for locations) from 2006 - 2010 . Semiannual amplitudes are plotted on a separate axis, under the model SST plots. 
Table 2. Each DR value, mean heat advection and mean surface net heat flux at points $1-3$.

\begin{tabular}{l|rcc}
\hline & Point 1 & Point 2 & Point 3 \\
\hline DR & 0.29 & 0.39 & 0.54 \\
DR of air temperature & 0.57 & 0.57 & 0.54 \\
Mean heat advection $\left(10^{12} \mathrm{~W}\right)$ & 269.89 & 10.41 & 0.65 \\
Mean surface net heat flux $\left(10^{10} \mathrm{~W}\right)$ & -15.60 & -0.43 & 2.82 \\
\hline
\end{tabular}

(a)

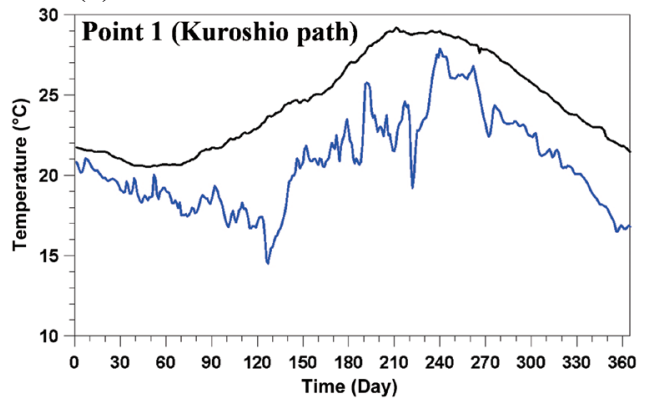

(c)

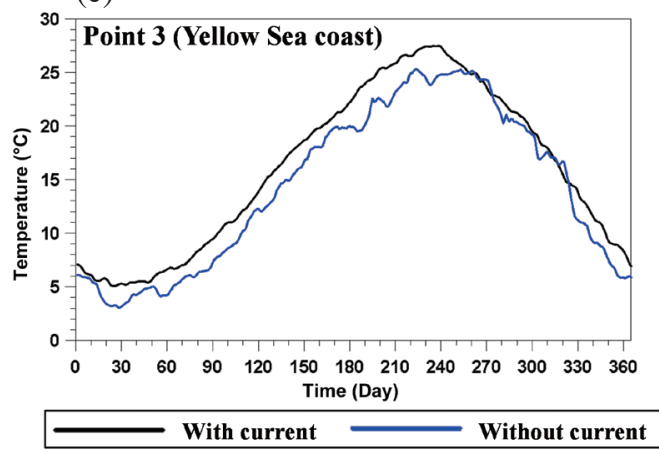

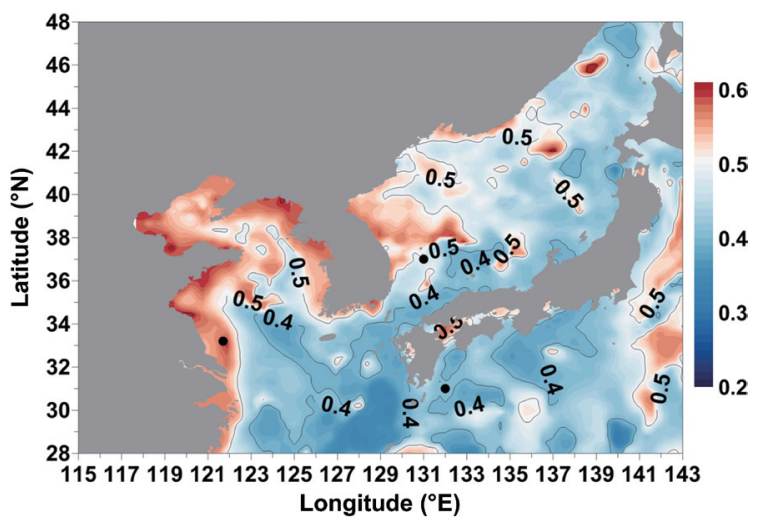

Fig. 13. Spatial DR distribution of model without ocean currents.

(b)

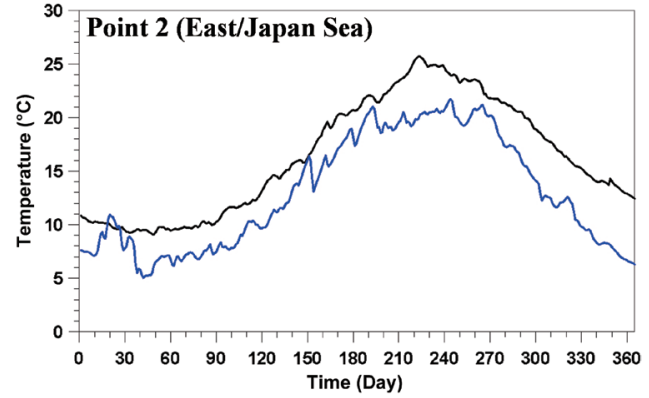

Fig. 14. Seasonal SST variations of model with and without ocean currents. See Fig. 8 for locations of points 1 - 3.

Table 3. DR of air temperature, SST with current, and SST without ocean currents at points $1-3$.

\begin{tabular}{l|ccc}
\hline & Point 1 & Point 2 & Point 3 \\
\hline DR of air temperature & 0.57 & 0.57 & 0.54 \\
DR of model result with currents & 0.30 & 0.39 & 0.54 \\
DR of model result without currents & 0.40 & 0.49 & 0.53 \\
\hline
\end{tabular}

surface $100-\mathrm{m}$ layer, it is not easy to quantify the relationship among the SST, ocean heat advection and surface heat fluxes. It might be possible to compare the SST, heat advection and surface heat flux more quantitatively if surface heat advection is calculated.
Acknowledgements This research was supported by SNUYonsei Research Cooperation Program through Seoul National University (SNU) in 2014 and the project titled "Long-term change of structure and function in marine ecosystems of Korea", funded by the Ministry of Oceans and Fisheries, Korea. 


\section{REFERENCES}

Ashkenazy, Y., Y. Feliks, H. Gildor, and E. Tziperman, 2008: Asymmetry of daily temperature records. J. Atmos.Sci., 65,3327-3336, doi: 10.1175/2008JAS2662.1. [Link]

Bartos, I. and I. M. Jánosi, 2005: Atmospheric response function over land: Strong asymmetries in daily temperature fluctuations. Geophys. Res. Lett., 32, L23820, doi: 10.1029/2005GL024559. [Link]

Bartos, I. and I. M. Jánosi, 2006: Nonlinear correlations of daily temperature records over land. Nonlinear Proc. Geoph., 13, 571-576.

Belkin, I. M., 2009: Rapid warming of large marine ecosystems. Prog. Oceanogr., 81, 207-213, doi: 10.1016/j. pocean.2009.04.011. [Link]

Cayan, D. R., 1992: Latent and sensible heat flux anomalies over the northern oceans: Driving the sea surface temperature. J. Phys. Oceanogr., 22, 859-881, doi: 10.1 175/1520-0485(1992)022<0859:LASHFA>2.0.CO;2. [Link]

Cho, Y. K., G. H. Seo, B. J. Choi, S. Kim, Y. G. Kim, Y. H. Youn, and E. P. Dever, 2009: Connectivity among straits of the northwest Pacific marginal seas. J. Geophys. Res., 114, C06018, doi: 10.1029/2008JC005218. [Link]

Cho, Y. K., G. H. Seo, C. S. Kim, B. J.Choi, and D. C. Shaha, 2013: Role of wind stress in causing maximum transport through the Korea Strait in autumn. J. Mar. Syst., 115-116, 33-39, doi: 10.1016/j.jmarsys.2013.02.002. [Link]

Dong, S., S. T. Gille, and J. Sprintall, 2007: An assessment of the southern ocean mixed layer heat budget. J. Climate, 20, 4425-4442, doi: 10.1175/JCLI4259.1. [Link]

Donlon, C. J., M. Martin, J. Stark, J. Roberts-Jones, E. Fiedler, and W. Wimmer, 2012: The Operational Sea Surface Temperature and Sea Ice Analysis (OSTIA) system. Remote Sens. Environ., 116, 140-158, doi: 10.1016/j.rse.2010.10.017. [Link]

Efimova, N. A., 1961: On methods of calculating monthly values of net long-wave radiation. Meteorol. Gidrol.,
10, 28-33. (in Russian)

Egbert, G. D. and S. Y. Erofeeva, 2002: Efficient inverse modeling of barotropic ocean tides. J. Atmos. Ocean. Technol., 19, 183-204, doi: 10.1175/1520-0426(2002) 019<0183:EIMOBO>2.0.CO;2. [Link]

Hirose, N., H. C. Lee, and J. H. Yoon, 1999: Surface heat flux in the East China Sea and the Yellow Sea. J. Phys. Oceanogr., 29, 401-417, doi: 10.1175/1520-0485(199 9)029<0401:SHFITE > 2.0.CO;2. [Link]

Kang, Y. Q., 1984: Influence of sea surface temperature on the annual variation of air temperature in Korea. J. Korean Met. Soc., 20, 73-81.

Kim, Y. S. and R. Kimura, 1995: Error evaluation of the bulk aerodynamic method for estimating heat flux over the sea. J. Korean Met. Soc., 31, 399-413.

Large, W. G., J. C. McWilliams, and S. C. Doney, 1994: Oceanic vertical mixing: A review and a model with a nonlocal boundary layer parameterization. Rev. Geophys., 32, 363-403, doi: 10.1029/94RG01872. [Link]

Seckel, G. R. and F. H. Beaudry, 1973: The radiation from sun and sky over the North Pacific Ocean (abstract). Eos, Trans., AGU, 54, 1114.

Seo, G. H., Y. K. Cho, and B. J. Choi, 2014: Variations of heat transport in the northwestern Pacific marginal seas inferred from high-resolution reanalysis. Prog. Oceanogr., 121, 98-108, doi: 10.1016/j.pocean.2013.10.005. [Link]

Subrahamanyam, D. B., R. Ramachandran, S. I. Rani, P. K. Kunhikrishnan, and B. P. Kumar, 2008: Intercomparison of air-sea interface fluxes over the Yellow Sea and Korea Strait: Impact of Tsushima warm current. Bound.-Layer Meteor., 127, 333-344, doi: 10.1007/ s10546-007-9248-8. [Link]

Wallace, J. M., T. P. Mitchell, and C. Deser, 1989: The influence of sea-surface temperature on surface wind in the Eastern Equatorial Pacific: Seasonal and interannual variability. J. Climate, 2, 1492-1499, doi: 10.1175/1 520-0442(1989)002<1492:TIOSST>2.0.CO;2. [Link]

Wang, R., T.Zuo, and K. Wang, 2003: The Yellow Sea Cold Bottom Water-an oversummering site for Calanus sinicus (Copepoda, Crustacea). J. Plankton Res., 25, 169-183, doi: 10.1093/plankt/25.2.169. [Link] 